\title{
Alternative definitions of chronic bronchitis and their correlation with CT parameters
}

This article was published in the following Dove Press journal:

International Journal of COPD

Jeong Uk Lim,' Ji-Hyun Lee, ${ }^{2}$ Tae-Hyung Kim, ${ }^{3}$ Jae Seung Lee, ${ }^{4}$ Sang-Do Lee, ${ }^{4}$ Yeon-Mok Oh, ${ }^{4}$ Chin Kook Rhee'

'Division of Pulmonary, Allergy and Critical Care Medicine, Department of Internal Medicine, Seoul St. Mary's Hospital, College of Medicine, The Catholic University of Korea, Seoul, Korea; ${ }^{2}$ Department of Internal Medicine, CHA Bundang Medical Center, CHA University, Seongnam, Korea; ${ }^{3}$ Division of Pulmonary and Critical Care Medicine, Department of Internal Medicine, Hanyang University Guri Hospital, Hanyang University College of Medicine, Guri, Korea; ${ }^{4}$ Department of Pulmonary and Critical Care Medicine and Clinical Research Center for Chronic Obstructive Airway Diseases, Asan Medical Center, University of Ulsan College of Medicine, Seoul, Korea

Correspondence: Yeon-Mok Oh Department of Pulmonary and Critical Care Medicine and Clinical Research Center for Chronic Obstructive Airway Diseases, Asan Medical Center, University of Ulsan College of Medicine, 88 Olympic-ro 43-gil, Songpa-gu, Seoul 05505, Korea

$\mathrm{Tel}+82230103136$

Fax +82 230106968

Email ymoh55@amc.seoul.kr

Chin Kook Rhee

Division of Pulmonary, Allergy and Critical Care Medicine, Department of Internal Medicine, Seoul St. Mary's Hospital, College of Medicine, The Catholic University of Korea, 222, Banpodaero, Seocho-gu, Seoul 0659I, Korea

Tel +82 222586067

Fax +82 225993589

Email chinkook77@gmail.com
Introduction: Phenotyping of chronic bronchitis (CB) using COPD assessment tool (CAT) scores and St George's Respiratory Questionnaire (SGRQ) has rarely been attempted. The present study defined CB using CAT 1 and 2 scores and the questions on the severity of cough and sputum from the SGRQ. Furthermore, the predictability of CT parameters was also assessed for each $\mathrm{CB}$ definition.

Materials and methods: Patients enrolled in the Korean Obstructive Lung Disease study from June 2005 to October 2015 were evaluated for this study. The patients were spirometrically diagnosed with COPD and had a smoking history of $>10$ pack-years. Volumetric CT scans were performed for each patient upon enrollment in the cohort. Two definitions of CB using CAT 1/2 scores and SGRQ questions were used to phenotype CB among the study patients. Receiver operating characteristic curve analysis was performed to estimate the predictability of CT parameters for the CB phenotypes.

Results: Using CAT 1/2 scores, 57 of 279 (20.4\%) patients had CB, and 178 of 573 (31.1\%) had CB when the SGRQ questions were used to phenotype it. Total CAT and SGRQ scores were significantly higher in the $\mathrm{CB}$ group than those in the non-CB group for both definitions of CB. Forced expiratory volume in 1 second was lower for both CAT-defined and SGRQ-defined $\mathrm{CB}$ than that in the non-CB group. Mean wall thickness was significantly higher for both $\mathrm{CB}$ groups than in the non-CB group. Expiratory lung volume was higher and mean lung density was significantly lower for the SGRQ-defined CB group than non-CB group.

Conclusion: The $2 \mathrm{CB}$ definitions using CAT scores and the SGRQ questions correlated with associated CT airway parameters. SGRQ-defined CB better reflected the accompaniment of small airway obstruction when compared with CAT-defined CB.

Keywords: chronic bronchitis, chronic obstructive pulmonary disease, chest CT

\section{Introduction}

Among COPD, chronic bronchitis (CB) occurs in 14\%-74\% of cases, depending on the particular definition used. ${ }^{1}$ Patients with $\mathrm{CB}$ are generally more symptomatic, with a higher COPD assessment tool (CAT) score, and have a lower quality of life, scoring higher on the total SGRQ. ${ }^{2,3}$ Many studies have also shown that impaired pulmonary function is more evident for the $\mathrm{CB}$ type. ${ }^{3}$ Forced expiratory volume in 1 second $\left(\mathrm{FEV}_{1}\right)$ and $\mathrm{FEV}_{1}$ /forced vital capacity (FVC) are lower for the $\mathrm{CB}$ type. ${ }^{1}$ Exacerbations and mortality are higher in patients with the CB type. ${ }^{1,2}$ In addition, total smoking packyears and proportion of current smokers are higher for the CB group than for patients with COPD but without CB. ${ }^{1,4}$

CT parameters have been evaluated to identify the clinical correlation to prognostic markers in patients with COPD and distinguish specific COPD phenotypes objectively. Wall area percentage of the bronchus is positively correlated with body 
mass index in patients with COPD and the air trapping index (ATI) is inversely correlated with 6-minute walk distance (6MWD). ${ }^{5}$ Studies have shown that $\mathrm{CB}$ increases bronchial wall thickness compared with non-CB, ${ }^{6}$ and bronchial wall area is larger than in the non-CB type. ${ }^{7} \mathrm{FEV}_{1}$ decreases with increasing mean bronchial wall thickness. ${ }^{8}$ On the other hand, increased emphysema index (EI) and percentage of low-attenuated area are higher for emphysema-predominant COPD than for bronchitic COPD. ${ }^{9,10}$

Cough and sputum for at least 3 months per year and for 2 consecutive years are the most widely used definitions of CB worldwide. ${ }^{4}$ In some studies, sputum for 3 months per year is also used as a definition for CB. ${ }^{11}$ The answers to the questions regarding cough and phlegm in the St George's Respiratory Questionnaire (SGRQ) have also been used as alternative definitions of CB. ${ }^{12,13}$ However, the classic definition of $\mathrm{CB}$ frequently has limitations in accurately phenotyping CB. For example, older males have difficulty understanding "2 consecutive years" and the resultant prevalence of CB in overall COPD seems to be lower than the reported prevalence worldwide in Korean patients with COPD. ${ }^{1,3}$ In addition, checking whether patients have had the complaint of sputum for 3 months per year requires mental effort for older patients to recall.

Patients with COPD have responded to different questionnaires, including the CAT and total SGRQ, for initial symptoms and quality of life assessments. Among the many questions, the questions on severity of cough and sputum overlap with the widely known definition of $\mathrm{CB}$, which, in turn, raises the possibility of utilizing it to phenotype $\mathrm{CB}$. In fact, the SGRQ questions on cough and sputum have been used to some extent. In 1 study, if the patient answered "most days of the week" or "several days of the week" to both questions regarding cough and phlegm, the patient was phenotyped into the CB group. ${ }^{12}$ Among CAT scores, CAT 1 is a question on the severity of cough, while CAT 2 is a question that assesses the severity of sputum. To our knowledge, these 2 questions have rarely been used to phenotype CB.

The aim of the present study was to define $\mathrm{CB}$ among patients with COPD using CAT 1 and 2 scores and the questions from the SGRQ on the severity of cough and sputum. The predictability of CT parameters for each CB phenotype was also assessed by receiving operating characteristic (ROC) curve analysis.

\section{Patients and methods}

\section{Patients}

Patients enrolled in the Korean Obstructive Lung Disease study cohort for which patients with COPD or asthma had been recruited from pulmonary clinics in 16 hospitals in South Korea from June 2005 to October 2015 were evaluated for this study. The study patients were spirometrically diagnosed with COPD, with postbronchodilator $\mathrm{FEV}_{1} / \mathrm{FVC}<0.7$, and had a smoking history of $>10$ pack-years. In addition, patients had no or minimal abnormalities on chest radiographs. Pulmonary function test (PFT) and CT scans were performed on the same day. The institutional review board of the participating hospitals approved use of the clinical and imaging data for evaluation. Written informed consent was obtained from each patient. The names of ethics committees were as follows: Asan Medical Center, Bundang CHA Hospital, Ewha Womans University Mokdong Hospital, Korea University Anam Hospital, Hanyang University Guri Hospital, Inje University Ilsan Paik Hospital, Kangbuk Samsung Hospital, Hallym University Kangnam Sacred Heart Hospital, Kangwon National University Hospital, Seoul National University Hospital, Seoul National University Bundang Hospital, Ajou University Hospital, Konkuk University Hospital, The Catholic University of Korea Yeouido St Mary's Hospital, The Catholic University of Korea Seoul St Mary's Hospital, and National Medical Center.

\section{CT}

Volumetric CT scans were performed in all patients with COPD at full inspiration and expiration using a 16-MDCT scanner (Somatom Sensation; Siemens Medical Systems, Erlangen, Germany). Scan parameters included $0.75-\mathrm{mm}$ collimation, 100 eff. mAs, and $140 \mathrm{kVp}$ with pitch of 1.0. Patients were scanned craniocaudally in a supine position. The scale of attenuation coefficients in this $\mathrm{CT}$ scanner ranges from -1,024 to 3,072 Hounsfield unit (HU). No intravenous contrast medium was used. Using the soft kernel (B30f; Siemens Medical Systems), the images were reconstructed from the thoracic inlet to the lung base. The whole lung images were extracted automatically, and the attenuation coefficient of the pixel was measured by in-house software. The cut-off level dividing normal lung density and a low-attenuation area was -950 HU. ${ }^{5,14}$

The mean lung density (MLD) and the volume fraction of the lung were calculated automatically using software. Airway dimensions were measured at the site near the origin of 4 segmental bronchi (LB1+2, RB1, LB10, and RB10). The ATI was defined as the ratio of MLD on expiration and inspiration.

A modified sharpening filter with a 393 kernel size was used for more accurate airway measurement.

Lumen area (LA), wall area (WA), and wall area percent (WA\%) were measured in each segmental bronchus. 
The WA $\%$ was defined as WA/(WA + LA $) \times 100$. The mean value of each dimension value was used for the statistical analysis. After the validation process using polyacryl tube, the software automatically discriminated the airway lumen and the inner and outer boundaries of the airway wall using the full-width-maximum method. ${ }^{15,16}$

\section{CB definitions}

Two definitions of $\mathrm{CB}$ were used. $\mathrm{CB}$ was defined using the answers to CAT questions 1 and 2 (questions on the severity of cough and sputum). As there is no reference, we aimed to find the CAT $1 / 2$ cut-off value to define CB. We analyzed the prevalence of $\mathrm{CB}$ for each CAT $1 / 2$ score.

Based on previous studies, responses to SGRQ questions were also used to define CB. ${ }^{12}$ Among the patients with COPD who answered the SGRQ questions, CB was defined when patients answered "most days of the week" or "several days of the week" to the questions "How often do you complain of cough during the week?" and "How often do you complain of sputum during the week?"

\section{Clinical parameters}

The patients' clinical parameters significant to COPD were also evaluated. In addition to the previously mentioned CAT and SGRQ scores, sex and age of patients were also included in the analyses. Total numbers of COPD-related visits to the hospital, outpatient visits, visits to the emergency room, and admissions were also evaluated. Exercise capacity on the 6MWD was also evaluated. $\mathrm{FEV}_{1}, \mathrm{FVC}$, and $\mathrm{FEV}_{1} / \mathrm{FVC}$ were evaluated from the results of the PFT. The diffusion capacity of the lungs for carbon monoxide (DLCO) was also evaluated.

\section{Statistical analysis}

All statistical analyses were performed using the Statistical Package for the Social Sciences software program version 18.0 (SPSS Inc., Chicago, IL, USA). Data of continuous variables are presented as mean with range. An ROC curve was constructed to estimate the predictability of the CT parameters for the $\mathrm{CB}$ phenotypes. The optimum cut-off values were defined as the point closest to the upper-left angle of the chart. The chi-square test was performed to compare categorical parameters. Continuous variables were analyzed using 2-sided tests or the Mann-Whitney test depending on the normality of the data distribution. A $P$-value $<0.05$ was considered significant.

\section{Results}

A total of 279 patients had CAT scores at enrollment in the cohort. Of the 279 patients, $235(84.2 \%)$ had CAT 1 and 2 scores $\geq 1$, and $125(44.8 \%)$ patients had CAT 1 and 2 scores $\geq 2$. Fifty-seven patients had CAT scores $\geq 3$ (20.4\%). When the CAT score cut-off was $<3$, the percentages of alleged patients with $\mathrm{CB}$ were too low compared with previously reported $\mathrm{CB}$ percentages, ${ }^{3}$ so only the $\mathrm{CB}$ group, defined as patients with COPD with a CAT score $\geq 3$, were evaluated in depth. Table 1 shows a comparison of the clinical characteristics of the $\mathrm{CB}$ and non-CB groups. Mean age of the patients with $\mathrm{CB}$ was $66.9 \pm 8.2$ years, and that for the non-CB group was $68.3 \pm 8.3(P>0.05)$. The percentage of males was lower in the CB group (89.5\% vs $92.8 \%$ ) $(P>0.05)$. The total CAT score was higher in the CB group $(21.8 \pm 5.7)$ than the non-CB group $(10.1 \pm 6.4)(P<0.001)$. Total SGRQ score was $39.4 \pm 18.9$ for the CB group, compared with $20.5 \pm 14.1$ for the non-CB group $(P<0.001)$. Total COPD-related hospital visits and outpatient visits tended to be more frequent in the $\mathrm{CB}$ group $(P>0.05)$. Mean $\mathrm{FEV}_{1}(\%)$ was $51.4 \pm 13.8$ in the $\mathrm{CB}$ group and $56.5 \pm 15.7$ in the non-CB group $(P=0.028)$. Mean FVC $(\%)$ also tended to be lower in the $\mathrm{CB}$ group $(80.4 \pm 14.7$ vs $83.1 \pm 14.4)$ than the non-CB group $(P>0.05)$. Mean wall thickness was higher for the $\mathrm{CB}$ group $(1.28 \pm 0.11 \mathrm{~mm})$ than the non-CB group $(1.24 \pm 0.11 \mathrm{~mm})(P=0.013)$. Mean WA was also higher for the CB group $(P=0.015)$.

Table 2 shows a comparison of clinical characteristics between the $\mathrm{CB}$ group defined by responses to the SGRQ questions and the non-CB group. Mean age of the $\mathrm{CB}$ group was $66.7 \pm 8.4$ years, and that of the non-CB group was $66.7 \pm 7.8(P>0.05)$. The male percentage was lower in the CB group than the non-CB group (91.6\% vs $92.2 \%)$ $(P>0.05)$. The percentage of current smokers was significantly higher in the $\mathrm{CB}$ group than the non- $\mathrm{CB}$ group $(39.3 \%$ vs $27.1 \%)(P=0.001)$. Total CAT score was higher in the CB group (15.8 \pm 8.4$)$ than the non-CB group (11.1 \pm 7.0$)$ $(P<0.001)$. Total SGRQ score was $39.4 \pm 18.6$ in the CB group, compared with $26.8 \pm 17.2$ in the non-CB group $(P<0.001)$. Total COPD-related hospital visits and outpatient visits tended to be higher in the $\mathrm{CB}$ group $(P>0.05)$. Mean $\mathrm{FEV}_{1}(\%)$ was $49.1 \pm 16.9$ in the $\mathrm{CB}$ group and 52.9 \pm 16.2 in the non-CB group $(P=0.012)$. Mean FVC $(\%)$ was not different between the groups. $\mathrm{FEV}_{1} / \mathrm{FVC}$ was significantly lower in the $\mathrm{CB}$ group $(44.9 \% \pm 11.6 \%)$ than the non-CB group $(48.2 \% \pm 11.6 \%)$. The absolute DLCO value was significantly lower in the $\mathrm{CB}$ group than the non-CB group $(P=0.048)$. Expiratory lung volume was higher $(P=0.002)$ and expiratory MLD was significantly lower in the CB group $(P<0.001)$ than the non-CB group. Furthermore, mean wall thickness was higher in the CB group $(1.24 \pm 0.12 \mathrm{~mm})$ than the non-CB group $(1.22 \pm 0.11 \mathrm{~mm})(P=0.047)$. 
Table I Clinical characteristics of COPD patients with CAT scores and comparison between non-chronic bronchitis and chronic bronchitis patients defined as CAT I and 2 scores $\geq 3$

\begin{tabular}{|c|c|c|c|c|}
\hline Characteristics & $\begin{array}{l}\text { Overall patients } \\
(n=279)\end{array}$ & $\begin{array}{l}\text { CB group } \\
(n=57)\end{array}$ & $\begin{array}{l}\text { Non-CB group } \\
(n=222)\end{array}$ & $P$-value \\
\hline Mean age (years, mean, SD) & $68.0 \pm 8.3$ & $66.9 \pm 8.2$ & $68.3 \pm 8.3$ & $0.24 I$ \\
\hline $\operatorname{Sex}(n, \%)$ & & & & 0.407 \\
\hline Female & $22(7.9 \%)$ & $6(10.5 \%)$ & $16(7.2 \%)$ & \\
\hline Male & $257(92.1 \%)$ & $5 \mathrm{I}(89.5 \%)$ & $206(92.8 \%)$ & \\
\hline \multicolumn{5}{|l|}{ Smoking } \\
\hline Current smoker (n, \%) & 81 (29\%) & $15(26.3 \%)$ & $66(29.7 \%)$ & 0.870 \\
\hline Pack-years (mean, SD) & $42.9 \pm 25.6$ & $46.7 \pm 29.4$ & $42.0 \pm 24.6$ & 0.253 \\
\hline Body mass index (mean, SD) & $24.3 \pm 2.6$ & $24.5 \pm 2.7$ & $24.2 \pm 2.6$ & 0.694 \\
\hline CAT total score (mean, SD) & $12.5 \pm 7.8$ & $21.8 \pm 5.7$ & $10.1 \pm 6.4$ & $<0.001$ \\
\hline SGRQ, total (mean, SD) & $24.2 \pm 16.8$ & $39.4 \pm 18.9$ & $20.5 \pm \mid 4.1$ & $<0.001$ \\
\hline Total visits to hospital & $2.7 \pm 4.3$ & $4.7 \pm 6.9$ & $1.6 \pm 1.2$ & 0.117 \\
\hline Outpatient visits & $2.8 \pm 4.9$ & $5.0 \pm 7.0$ & $1.3 \pm 1.6$ & 0.099 \\
\hline Emergency room visits & $0.9 \pm 1.0$ & $0.6 \pm 1.0$ & $1.1 \pm 1.0$ & 0.284 \\
\hline Admissions to hospital & $1.0 \pm 0.9$ & $0.9 \pm 0.8$ & $1.0 \pm 0.9$ & 0.662 \\
\hline FEV (absolute, L) & $1.6 \pm 0.6$ & $1.5 \pm 0.5$ & $1.7 \pm 0.6$ & 0.025 \\
\hline $\mathrm{FEV}_{\text {, }}$ (percentage predicted) & $55.4 \pm 15.4$ & $51.4 \pm 13.8$ & $56.5 \pm 15.7$ & 0.028 \\
\hline FVC (absolute value, L) & $3.4 \pm 0.8$ & $3.3 \pm 0.8$ & $3.5 \pm 0.8$ & 0.070 \\
\hline FVC (percentage predicted) & $82.6 \pm \mid 4.4$ & $80.4 \pm 14.7$ & $83.1 \pm 14.4$ & 0.215 \\
\hline $\mathrm{FEV}_{\mathrm{I}} / \mathrm{FVC}$ (percentage) & $47.9 \pm 11.1$ & $46.2 \pm 10.9$ & $48.3 \pm 11.1$ & 0.217 \\
\hline DLCO, absolute & $14.6 \pm 7.8$ & $13.6 \pm 4.5$ & $14.8 \pm 8.4$ & 0.332 \\
\hline DLCO, percentage predicted & $71.8 \pm 20.8$ & $71.6 \pm 20.5$ & $71.8 \pm 20.9$ & 0.958 \\
\hline 6MW (distance, meter) & $403.3 \pm 84.6$ & $398.9 \pm 89.4$ & $404.5 \pm 83.5$ & 0.671 \\
\hline \multicolumn{5}{|l|}{ CT parameters } \\
\hline Inspiratory lung volume $\left(\mathrm{cm}^{3}\right)$ & $5,291.3 \pm 1,054.9$ & $5,201.6 \pm I, \mid 88.0$ & $5,3|4.7 \pm 1,0| 9.2$ & 0.484 \\
\hline Expiratory lung volume $\left(\mathrm{cm}^{3}\right)$ & $3,7 \mid 8.4 \pm 1,050.5$ & $3,728.4 \pm 975.6$ & $3,7|5.8 \pm 1,07| .3$ & 0.937 \\
\hline Inspiratory MLD (HU) & $-870.9 \pm 26.1$ & $-868.2 \pm 29.2$ & $-871.5 \pm 25.2$ & 0.406 \\
\hline Expiratory MLD (HU) & $-817.9 \pm 45.3$ & $-820.7 \pm 42.6$ & $-817.2 \pm 46.0$ & 0.614 \\
\hline ATI & $0.917 \pm 0.141$ & $0.943 \pm 0.035$ & $0.911 \pm 0.155$ & 0.169 \\
\hline Inspiratory El (\%) & $15.8 \pm 12.2$ & $15.5 \pm 13.1$ & $15.8 \pm 11.9$ & 0.847 \\
\hline Expiratory El (\%) & $8.5 \pm 9.8$ & $8.5 \pm 9.7$ & $8.6 \pm 9.8$ & 0.957 \\
\hline Airway lumen diameter (mm) & $3.5 \pm 1.4$ & $3.6 \pm 0.7$ & $3.5 \pm 1.5$ & 0.783 \\
\hline Mean wall thickness (mm) & $1.24 \pm 0.12$ & $1.28 \pm 0.1 \mathrm{I}$ & $1.24 \pm 0.11$ & 0.013 \\
\hline Mean wall area $\left(\mathrm{mm}^{2}\right)$ & $18.7 \pm 3.8$ & $19.8 \pm 4.5$ & $18.4 \pm 3.6$ & 0.015 \\
\hline Mean wall area (\%) & $66.1 \pm 4.9$ & $66.2 \pm 5.1$ & $66.0 \pm 4.9$ & 0.852 \\
\hline
\end{tabular}

Abbreviations: 6MW, 6-minute walk; ATI, air trapping index; CAT, COPD assessment test; CB, chronic bronchitis; CT, computed tomography; DLCO, diffuse capacity of the lungs for carbon monoxide; El, emphysema index; FEV , forced expiratory volume in I s; FVC, forced vital capacity; HU, Hounsfield unit; L, liters; MLD, mean lung density; SGRQ, St George's Respiratory Questionnaire.

Table 3 shows the results of the ROC curve analysis performed to evaluate the predictability of the CT parameters for $\mathrm{CB}$ phenotypes. For CAT-defined CB, mean wall thickness and mean WA were the CT parameters with statistical significance. Mean wall thickness showed an area under the curve (AUC) of 0.632 (95\% CI, 0.550-0.713) with specificity of 0.797 at a cut-off value of $1.30 \mathrm{~mm}$. Mean WA showed an AUC of 0.598 with sensitivity of 0.722 at a cut-off value of $17.27 \mathrm{~mm}^{2}$. For SGRQ-defined CB, expiratory lung volume, MLD, EI, and the ATI were the significant CT parameters in the ROC curve analysis. All values had AUCs $>0.5$.

\section{Discussion}

The present study attempted to phenotype CB using the responses to SGRQ questions and CAT scores on cough and sputum, and compared the clinical characteristics between $\mathrm{CB}$ and non-CB patients with COPD. In addition to $\mathrm{CB}$ phenotyping, the predictability of $\mathrm{CT}$ parameters for $\mathrm{CB}$ among patients with COPD was assessed by an ROC curve analysis. The clinical characteristics of the $\mathrm{CB}$ group defined using CAT scores and responses to the SGRQ matched the patients with $\mathrm{CB}$ from previous studies. . $^{2,312} \mathrm{We}$ also showed that patients with $\mathrm{CB}$ have higher $\mathrm{CAT}$ scores and lower quality of life than those of the non-CB group. $\mathrm{FEV}_{1}$ was 
Table 2 Comparison of clinical characteristics between non-chronic bronchitis and chronic bronchitis patients defined by responses to SGRQ questions on cough and sputum

\begin{tabular}{|c|c|c|c|c|}
\hline Characteristics & $\begin{array}{l}\text { Overall patients } \\
(n=573)\end{array}$ & $\begin{array}{l}\text { CB group } \\
(n=178)\end{array}$ & $\begin{array}{l}\text { Non-CB group } \\
(n=395)\end{array}$ & $P$-value \\
\hline Mean age (years, mean, SD) & $66.7 \pm 8.0$ & $66.7 \pm 8.4$ & $66.7 \pm 7.8$ & 0.955 \\
\hline $\operatorname{Sex}(n, \%)$ & & & & 0.813 \\
\hline Female & $46(8.0 \%)$ & $15(8.4 \%)$ & $31(7.8 \%)$ & \\
\hline Male & $527(92.0 \%)$ & $163(91.6 \%)$ & 364 (92.2\%) & \\
\hline \multicolumn{5}{|l|}{ Smoking } \\
\hline Current smoker (n, \%) & 177 (30.9\%) & 70 (39.3\%) & $107(27.1 \%)$ & 0.001 \\
\hline Pack-years (mean, SD) & $44.1 \pm 27.4$ & $44.6 \pm 26.1$ & $43.9 \pm 27.9$ & 0.810 \\
\hline Body mass index (mean, SD) & $23.7 \pm 3.1$ & $22.5 \pm 3.1$ & $24.1 \pm 3.0$ & 0.003 \\
\hline CAT total score (mean, SD) & $12.6 \pm 7.8$ & $15.8 \pm 8.4$ & II.I \pm 7.0 & $<0.001$ \\
\hline SGRQ, total (mean, SD) & $30.7 \pm 18.6$ & $39.4 \pm 18.6$ & $26.8 \pm 17.2$ & $<0.001$ \\
\hline Total visits to hospital & $3.4 \pm 4.2$ & $4.1 \pm 5.2$ & $2.8 \pm 2.9$ & 0.105 \\
\hline Outpatient visits & $3.5 \pm 4.4$ & $3.9 \pm 5.2$ & $3.1 \pm 3.4$ & 0.337 \\
\hline Emergency room visits & $0.8 \pm 0.9$ & $0.8 \pm 1.0$ & $0.9 \pm 0.9$ & 0.680 \\
\hline Admissions to hospital & $1.2 \pm 0.7$ & $1.3 \pm 0.7$ & $1.1 \pm 0.7$ & 0.239 \\
\hline $\mathrm{FEV}_{\text {, (absolute, L) }}$ & $1.5 \pm 0.6$ & $1.4 \pm 0.5$ & $1.6 \pm 5.8$ & 0.003 \\
\hline $\mathrm{FEV}_{\text {, (percentage predicted) }}$ & $51.7 \pm 16.5$ & $49.1 \pm 16.9$ & $52.9 \pm 16.2$ & 0.012 \\
\hline FVC (absolute value, L) & $3.3 \pm 0.8$ & $3.2 \pm 0.9$ & $3.3 \pm 0.8$ & 0.364 \\
\hline FVC (percentage predicted) & $78.9 \pm 16.2$ & $79.0 \pm 17.4$ & $78.9 \pm 15.7$ & 0.936 \\
\hline $\mathrm{FEV}_{1} / \mathrm{FVC}$ (percentage) & $47.1 \pm 11.7$ & $44.9 \pm 11.6$ & $48.2 \pm 11.6$ & 0.002 \\
\hline DLCO, absolute & $15.0 \pm 7.0$ & $14.1 \pm 5.6$ & $15.4 \pm 7.5$ & 0.048 \\
\hline DLCO, percentage predicted & $77.8 \pm 24.0$ & $75.0 \pm 22.3$ & $79.0 \pm 24.6$ & 0.065 \\
\hline 6MW (distance, meter) & $421.5 \pm 90.3$ & $4 \mid 4.5 \pm 88.6$ & $424.6 \pm 91.0$ & 0.233 \\
\hline Body fat percentage (\%) & $25.9 \pm 6.7$ & $23.9 \pm 6.1$ & $26.6 \pm 6.8$ & 0.026 \\
\hline \multicolumn{5}{|l|}{ CT parameters } \\
\hline Inspiratory lung volume $\left(\mathrm{cm}^{3}\right)$ & $5,503 . I \pm I, I 27.3$ & $5,547.5 \pm I, 194.6$ & $5,483.2 \pm 1,096.7$ & 0.536 \\
\hline Expiratory lung volume $\left(\mathrm{cm}^{3}\right)$ & $3,895.2 \pm I, \mid 140.8$ & $4,117.4 \pm 1,163.7$ & $3,795.2 \pm 1,117.6$ & 0.002 \\
\hline Inspiratory MLD (HU) & $-877.3 \pm 27.4$ & $-878.4 \pm 27.1$ & $-876.8 \pm 27.6$ & 0.532 \\
\hline Expiratory MLD (HU) & $-825.7 \pm 47.2$ & $-835.7 \pm 42.1$ & $-821.2 \pm 48.7$ & $<0.001$ \\
\hline ATI & $0.905 \pm 0.185$ & $0.914 \pm 0.188$ & $0.90 I \pm 0.184$ & 0.439 \\
\hline Inspiratory El (\%) & $18.9 \pm 14.7$ & $19.8 \pm 14.3$ & $18.4 \pm 14.8$ & 0.299 \\
\hline Expiratory El (\%) & $10.8 \pm 12.4$ & $12.1 \pm 12.0$ & $10.2 \pm 12.5$ & $0.08 \mathrm{I}$ \\
\hline Airway lumen diameter (mm) & $3.4 \pm 1.1$ & $3.4 \pm 0.6$ & $3.4 \pm 1.2$ & 0.634 \\
\hline Mean wall thickness (mm) & $1.23 \pm 0.12$ & $1.24 \pm 0.12$ & $1.22 \pm 0.11$ & 0.047 \\
\hline Mean wall area $\left(\mathrm{mm}^{2}\right)$ & $17.9 \pm 3.7$ & $18.2 \pm 4.0$ & $17.8 \pm 3.6$ & 0.262 \\
\hline Mean wall area (\%) & $66.3 \pm 5.0$ & $66.8 \pm 5.0$ & $66.1 \pm 4.9$ & 0.143 \\
\hline
\end{tabular}

Note: Data are presented as mean \pm standard deviation.

Abbreviations: 6MW, 6-minute walk; ATI, air trapping index; CAT, COPD assessment test; CB, chronic bronchitis; CT, computed tomography; DLCO, diffuse capacity

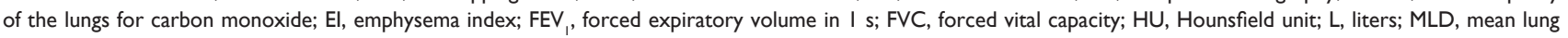
density; SGRQ, St George's Respiratory Questionnaire.

Table 3 The optimum cutoff and ROC curve parameters for the prediction of chronic bronchitis type, defined by the CAT scores or SGRQ responses

\begin{tabular}{|c|c|c|c|c|c|}
\hline Parameters & Cutoff & Sensitivity & Specificity & AUC & $95 \% \mathrm{Cl}$ \\
\hline \multicolumn{6}{|l|}{ CAT-defined CB } \\
\hline Mean wall thickness & 1.30 & 0.426 & 0.797 & 0.632 & $0.550-0.713$ \\
\hline Mean wall area & 17.27 & 0.722 & 0.449 & 0.598 & $0.512-0.683$ \\
\hline \multicolumn{6}{|l|}{ SGRQ-defined CB } \\
\hline Expiratory lung volume & $3,571.2$ & 0.678 & 0.468 & 0.583 & $0.531-0.634$ \\
\hline Expiratory MLD & -807.23 & 0.368 & 0.801 & 0.585 & $0.535-0.635$ \\
\hline Expiratory El & 2.17 & 0.789 & 0.366 & 0.576 & $0.526-0.626$ \\
\hline ATI & 0.926 & 0.781 & 0.377 & 0.592 & $0.543-0.64 I$ \\
\hline
\end{tabular}

Note: Only the CT parameters with $P$-value $<0.05$ are shown in the table.

Abbreviations: ATI, air trapping index; AUC, area under the curve; CAT, COPD assessment test; CB, chronic bronchitis; El, emphysema index; MLD, mean lung density; ROC, receiving operating characteristic; SGRQ, St George's Respiratory Questionnaire. 
lower and COPD-related hospital visits were higher in the CB group. The percentage of current smokers at enrollment in the cohort was higher in the CB group, which was consistent with a previous study on $\mathrm{CB} .^{10}$

The correlation between CB phenotype and CT parameters differed when the 2 definitions of $\mathrm{CB}$ were applied. When CAT scores were used for the CB definition, mean WA and mean wall thickness were significantly higher in the $\mathrm{CB}$ group than those in the non-CB group, while the AUC of mean wall thickness was $>0.6$. Previous studies also showed that mean wall thickness and mean WA of the bronchus increased in patients with COPD and CB. ${ }^{6,7}$ When the SGRQ definition was used, mean wall thickness was also higher in the CB group. While inspiratory lung volume and MLD were not significantly different between the 2 groups, expiratory lung volume was significantly higher and MLD was significantly lower in the CB group. The differences between the groups in the expiratory CT findings suggested that small-airway disease coexists with $\mathrm{CB}$ as defined by the SGRQ questions.

The classic definition of $\mathrm{CB}$ and the new definition based on CAT answers suggested in our study both categorize $\mathrm{CB}$ according to severity of cough and sputum, which are the main complaints of $\mathrm{CB}$ patients. The classic definition focuses on the duration of the symptoms, on the other hand, the alternative definition focuses on how severe the symptoms are at the time of presentation.

Nevertheless, COPD patients, mostly elderly, experience difficulties in answering the question "Cough, sputum for 3 months per year for 2 consecutive years". Furthermore, the term " 2 consecutive years" is difficult to translate into Korean without changing the original meaning, because there is no precise word in Korean that equates to "consecutive" in this case. ${ }^{11}$ Considering the challenge from language difference, a more simple and easier definition will improve diagnosis of $\mathrm{CB}$ patients. The responses to the CAT questions depend on patients' subjective feelings and can be influenced by patient-related factors. However, we assume that the alternative definition will be more intuitive and easier for patients to answer in busy outpatients clinics.

In previous studies, the SGRQ questions were also used to define $\mathrm{CB} \cdot{ }^{12,13}$ In $\mathrm{CB}$, both SGRQ and CAT scores are significantly increased. ${ }^{3}$ SGRQ has many questions and is used more in the research setting. On the other hand, the CAT has only 8 questions and is more frequently used in the outpatient clinics. ${ }^{17}$ For this reason, the novel definition of CB based on CAT scores can be more practical in clinical settings compared with the classic definition and the SGRQ CB definition.
There are limitations, which are worthy of being mentioned. First, the CB definition based on CAT scores is novel and requires further validation process. Comparative studies would evaluate coherence with other CB definitions. In addition, cutoffs in the CAT scores should also be determined. Second, we have not used the classic definition of $\mathrm{CB}$ for comparison in our study due to the low percentage of patients who properly responded. Finally, the present study is a crosssectional work, and a future study following clinical courses of $\mathrm{CB}$ patients is necessary to evaluate whether the new $\mathrm{CB}$ definition is appropriate for management of COPD patients.

\section{Conclusion}

When focusing on clinical characteristics of the patients with $\mathrm{CB}$ defined by the 2 different methods, both $\mathrm{CB}$ groups showed clinical characteristics consistent with the CB phenotypes reported from previous studies: more respiratory symptoms, lower quality of life, impaired pulmonary function, and a higher percentage of current smokers. Both the CAT- and SGRQ-defined CB groups correlated with associated CT airway parameters. The CT parameters associated with SGRQ-defined CB better reflect the accompaniment of small airway obstruction when compared with CAT-defined CB.

\section{Disclosure}

The authors report no conflicts of interest in this work.

\section{References}

1. Corhay JL, Vincken W, Schlesser M, Bossuyt P, Imschoot J. Chronic bronchitis in COPD patients is associated with increased risk of exacerbations: a cross-sectional multicentre study. Int J Clin Pract. 2013; 67(12):1294-1301.

2. de Oca MM, Halbert RJ, Lopez MV, et al. The chronic bronchitis phenotype in subjects with and without COPD: the PLATINO study. Eur Respir J. 2012;40(1):28-36.

3. Choi JY, Yoon HK, Park SJ, et al. Chronic bronchitis is an independently associated factor for more symptom and high-risk groups. Int J Chron Obstruct Pulmon Dis. 2016;11:1335-1341.

4. Agusti A, Calverley PM, Celli B, et al; Evaluation of COPD Longitudinally to Identify Predictive Surrogate Endpoints (ECLIPSE) investigators. Characterization of COPD heterogeneity in the ECLIPSE cohort. Respir Res. 2010;11:122.

5. Lee YK, Oh YM, Lee JH, et al. Quantitative assessment of emphysema, air trapping, and airway thickening on computed tomography. Lung. 2008; 186(3):157-165.

6. Mair G, Maclay J, Miller JJ, et al. Airway dimensions in COPD: relationships with clinical variables. Respir Med. 2010;104(11):1683-1690.

7. Orlandi I, Moroni C, Camiciottoli G, et al. Chronic obstructive pulmonary disease: thin-section CT measurement of airway wall thickness and lung attenuation. Radiology. 2005;234(2):604-610.

8. Halper-Stromberg E, Cho MH, Wilson C, et al. Visual assessment of chest computed tomographic images is independently useful for genetic association analysis in studies of chronic obstructive pulmonary disease. Ann Am Thorac Soc. 2017;14(1):33-40.

9. Camiciottoli G, Bigazzi F, Bartolucci M, et al. BODE-index, modified BODE-index and ADO-score in chronic obstructive pulmonary disease: relationship with COPD phenotypes and CT lung density changes. COPD. 2012;9(3):297-304. 
10. Kim V, Davey A, Comellas AP, et al; COPDGene ${ }^{\circledR}$ Investigators. Clinical and computed tomographic predictors of chronic bronchitis in COPD: a cross sectional analysis of the COPDGene study. Respir Res. 2014;15:52.

11. Lee HY, Kim JW, Lee SH, et al. Lower diffusing capacity with chronic bronchitis predicts higher risk of acute exacerbation in chronic obstructive lung disease. J Thorac Dis. 2016;8(6):1274-1282.

12. Kim V, Sternberg AL, Washko G, et al; National Emphysema Treatment Trial Research Group. Severe chronic bronchitis in advanced emphysema increases mortality and hospitalizations. COPD. 2013;10(6):667-678.

13. Kim V, Crapo J, Zhao H, et al; COPDGene Investigators. Comparison between an alternative and the classic definition of chronic bronchitis in COPDGene. Ann Am Thorac Soc. 2015;12(3):332-339.
14. Gevenois PA, de Maertelaer V, De Vuyst P, Zanen J, Yernault JC Comparison of computed density and macroscopic morphometry in pulmonary emphysema. Am J Respir Crit Care Med. 1995;152(2): 653-657.

15. Amirav I, Kramer SS, Grunstein MM, Hoffman EA. Assessment of methacholine-induced airway constriction by ultrafast highresolution computed tomography. J Appl Physiol (1985). 1993;75(5): 2239-2250.

16. Block M, Liu YH, Harris LD, Robb RA, Ritman EL. Quantitative analysis of a vascular tree model with the dynamic spatial reconstructor. J Comput Assist Tomogr. 1984;8(3):390-400.

17. Broaddus C, Mason RJ, Ernst JD, et al. Murray and Nadel's Textbook of Respiratory Medicine, 6th ed. Elsevier Saunders; 2016:768.

\section{Publish your work in this journal}

The International Journal of COPD is an international, peer-reviewed journal of therapeutics and pharmacology focusing on concise rapid reporting of clinical studies and reviews in COPD. Special focus is given to the pathophysiological processes underlying the disease, intervention programs, patient focused education, and self management protocols.

\section{Dovepress}

This journal is indexed on PubMed Central, MedLine and CAS. The manuscript management system is completely online and includes a very quick and fair peer-review system, which is all easy to use. Visit http://www.dovepress.com/testimonials.php to read real quotes from published authors.

Submit your manuscript here: http://www.dovepress.com/international-journal-of-chronic-obstructive-pulmonary-disease-journal 